\title{
Teaching Learning Curves In An Undergraduate Economics Or Operations Management Course
}

Jaideep T. Naidu, Philadelphia University, USA John F. Sanford, Philadelphia University, USA

\begin{abstract}
Learning Curves has its roots in economics and behavioral psychology. Learning Curves theory has several business applications and is widely used in the industry. As faculty of Operations Management courses, we cover this topic in some depth in the classroom. In this paper, we present some of our teaching methods and material that have helped us in communicating the learning curves concept. The students have found these very helpful in grasping the concepts better. We present comparative charts that highlight the key differences among the three standard methods for learning curve calculations. Students find these comparative charts to be very helpful in understanding these methods and in choosing the least time-consuming method when a problem can be solved in more than one way - often important during a time based exam. Furthermore, we point out an error and an ambiguity in textbooks and also provide some insights into the formula method.
\end{abstract}

Keywords: Learning Curves; Pedagogy

\section{INTRODUCTION}

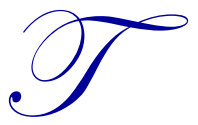

he subject of Learning Curves is discussed in most Operations Management textbooks. It has important applications in a number of areas, such as pricing new products, manpower planning and scheduling, capacity planning, and negotiated purchasing. A partial list of such textbooks is given in Krajewski, Ritzman, and Malhotra (2010); Martinich (1997), and Stevenson (2011). There have also been several recently published scholarly articles (Bai et al., 2012; and Rudek, 2011) that incorporate the learning effect in machine scheduling problems. In today's dynamic workplace, change occurs rapidly. When there is change, there also is learning. With instruction and repetition, workers learn to perform jobs more efficiently and thereby reduce the number of direct labor hours per unit. The learning effect can be represented by a line called a learning curve, which displays the relationship between the total direct labor per unit and the cumulative quantity of a product or service produced. The learning curve relates to a repetitive job or task and represents the relationship between experience and productivity; i.e., the time required to produce a unit decreases as the operator or firm produces more units.

The learning curve was first developed in the aircraft industry prior to World War II when analysts discovered that the direct labor input per airplane declined with considerable regularity as the cumulative number of airplanes produced increased. Among pioneers to discover this learning effect was Wright (1936). Learning curves enable managers to project the manufacturing cost per unit for any cumulative production quantity. Firms strive to move down the learning curve (lower labor hours per unit or lower costs per unit) by increasing volume. As cumulative production increases, costs (and prices) fall. The first companies in the market have a big advantage because newcomers must start selling at low prices and suffer initial losses.

In this paper, we first mention experiential and role-playing activities suggested by pedagogical researchers. We then present the three standard methods of learning curves calculations. Later, we point out some ambiguities in textbooks and supply arguments. We then present comparative charts to highlight and clarify the key 
differences of the three standard methods. These charts are not available in textbooks and students found them to be very helpful to understand the three standard methods.

\section{Role-Playing Exercises}

Making learning curves "real" to students can be a difficult task. This difficulty may be overcome by using an experiential classroom exercise. In our Operations Management courses, we explain the concept of Learning Curves using a hands-on learning exercise developed by Heineke and Meile (1995). This exercise introduces the students to learning curves and continuous improvement concepts. It also keeps them involved and interested as they can see for themselves their improvement in time when they repeat a given task. For another proposed hands-on activity using LEGO building block sets, see Paxton (2003). We also discuss the importance of learning curves by presenting some real world examples usually found in textbooks. Then we introduce our students to learning curves based calculations. A brief overview of the three standard methods follows.

\section{Standard Methods of Learning Curves Calculations}

A common problem is the task to find the time that the $n$th unit takes when the learning curve percentage and the time taken by the $k$ th unit are known. The following are three standard methods of learning curves based calculations presented in textbooks:

1. Learning Curve Property: By convention, learning curves are referred to in terms of the complements of their improvement rates. For example, a $90 \%$ (or $n \%$ ) learning curve (LC) denotes a $10 \%($ or $(100-n) \%)$ decrease in unit (or average) time with each doubling of repetitions. This means that if $U_{1}$ is known, then this property could be used to compute $U_{2}, U_{4}, U_{8}$ and so on. Or if $U_{3}$ is known, then $U_{6}, U_{12}, U_{24}$, and so on, can be calculated.

2. Table of Values: The table provided in textbooks shows two columns for some selected learning percentages. The first column enables us to determine how long a specific individual unit will take to be completed. The second column is cumulative and it enables us to compute the total time needed to complete a given number of repetitions. Note that textbooks typically provide a Table of values for up to 30 units for specific learning percentages; e.g., 70\%, 75\%, 80\%, 85\%, and $90 \%$.

3. The Formula Approach: The formula is based on the existence of a linear relationship between the time per unit and the number of units when these two variables are expressed in logarithms (log or ln). The unit time (i.e., the number of direct labor hours required) for the $n$th unit can be computed using the formula:

$U_{n}=U_{1} * n^{b}$

where $U_{n}=$ time for $n$th unit, $U_{1}=$ time for $1^{\text {st }}$ unit, and $\mathrm{b}=\log$ (learning rate) $/ \log 2$.

It is easy to see that each of the above methods has certain limitations, but it may not be immediately obvious to an undergraduate student to choose the fastest method when a problem can be solved in more than one way. Our proposed comparative charts presented in this paper have helped our students to clearly differentiate between these methods.

\section{Ambiguity in Textbooks}

We discuss some ambiguity in textbooks and present our arguments. The first is an error in the case of the Table of values. The second is an ambiguity in the case of the formula approach.

\section{Error}

Let $\mathrm{U}_{5}=10$ hours and $\mathrm{LC}=80 \%$. Find $\mathrm{U}_{8}$. It is noteworthy to mention that textbooks suggest that $\mathrm{U}_{1}$ needs to be found first by using the Table of values or the Formula. This is incorrect because $\mathrm{U}_{8}$ can be calculated without having to first find $U_{1}$. However, we emphasize to the student that $U_{1}$ needs to be obtained first only if a later calculation involves computing the cumulative time to produce a set of units. 
Ambiguity

Let $\mathrm{U}_{5}=10$ hours and $\mathrm{LC}=80 \%$. Find $\mathrm{U}_{8}$. All textbooks provide the formula $U_{n}=U_{1} * n^{\mathrm{b}}$ to calculate the $n$th unit. This gives students an impression that $U_{1}$ has to first be found in order to calculate $U_{8}$. This confusion is due to the lack of sufficient detail in textbooks. We provide the following insight to our students and explain that $\mathrm{U}_{8}$ can be obtained without calculating $\mathrm{U}_{1}$. According to the formula $\mathrm{U}_{5}=\mathrm{U}_{1} * 5^{\mathrm{b}} \Rightarrow \mathrm{U}_{1}=\mathrm{U}_{5} / 5^{\mathrm{b}}$ and $\mathrm{U}_{8}=\mathrm{U}_{1} * 8^{\mathrm{b}} \Rightarrow \mathrm{U}_{1}=$ $\mathrm{U}_{8} / 8^{\mathrm{b}}$. Thus, $\mathrm{U}_{5} / 5^{\mathrm{b}}=\mathrm{U}_{8} / 8^{\mathrm{b}} \Rightarrow \mathrm{U}_{8}=\mathrm{U}_{5} *(8 / 5)^{\mathrm{b}}$. This results in the general formula $\mathrm{U}_{n}=\mathrm{U}_{k} *(n / k)^{b}$ that is intuitive but not found in textbooks.

We now present the main section of this paper where we compare the three methods.

\section{THE THREE STANDARD METHODS - COMPARISONS}

Textbooks do not list the key advantages and limitations of each of the three standard methods and it is left to the reader to be inferred. Hence, students are confused about choosing the least time-consuming method to answer a question on a time-based exam. This prompted us to clarify these methods by presenting them in the form of comparative charts. Our students have found these charts to be very helpful in increasing their understanding of these methods. We first present Table 1 with numerical examples where the task is to calculate $\mathrm{U}_{n}$. We state whether it is possible or not possible for each of the three methods to calculate $\mathrm{U}_{n}$.

Table 1: To find $\mathrm{U}_{n}$ when $\mathrm{U}_{k}$ and $\mathrm{LC}$ are Given

\begin{tabular}{|l|l|l|l|}
\hline \multicolumn{1}{|l|}{ Examples } & a. Property & c. Formula \\
\hline $\begin{array}{l}1 . \mathrm{LC}=80 \% \text { and } \\
\mathrm{U}_{\mathrm{k}}=K \text { hours. } \\
\text { Calculate } \mathrm{U}_{n} .\end{array}$ & $\begin{array}{l}\text { Possible if } n \text { is one of the } \\
\text { numbers in the doubling } \\
\text { process }\end{array}$ & $\begin{array}{l}\text { Possible depending on the } \\
\text { number of units provided on } \\
\text { the Table of values }\end{array}$ & Possible \\
\hline \begin{tabular}{l|l|l|}
$2 . \mathrm{LC}=72 \%$ and \\
$\mathrm{U}_{\mathrm{k}}=K$ hours. \\
Calculate $\mathrm{U}_{n}$.
\end{tabular} & $\begin{array}{l}\text { Possible if } n \text { is one of the } \\
\text { numbers in the doubling } \\
\text { process }\end{array}$ & Not Possible & Possible \\
\hline
\end{tabular}

Notes (for Table 1):

(a) $K$ denotes a known value.

(b) We use $\mathrm{LC}=80 \%$ as an example for which its unit values are given in the Table of values in textbooks.

(c) We use LC $=72 \%$ as an example for which its unit values are not given in the Table of values in textbooks. However, we make sure our students understand that a table of values for any LC and for any number of units can be created rather easily using a spreadsheet.

We now present more examples to increase the students' understanding of these methods.

Example 1: Given $U_{6}=10$ hours and $L C=80 \%$, what other unit times can be found using the property?

Typical Student Response: $\mathrm{U}_{12}, \mathrm{U}_{24}, \mathrm{U}_{48}$, and so on, can be found.

Almost all the time, students move forward in this doubling of repetitions process of the property. They miss the fact that even $\mathrm{U}_{3}$ can be found. Hence, this point is stressed.

Example 2: Given $U_{6}=10$ hours and $L C=80 \%$, what is the value of $U_{8}$ ?

Typical Student Response: A Table of values or the formula can be used.

We observe that most students prefer using the Table of values. It is a good idea to show that using the formula takes about the same time, and if there are slight variations in the above question, then only the formula can be used. For instance, if $\mathrm{LC}=72 \%$ or if one is required to calculate $\mathrm{U}_{50}$, the Table of values from a textbook cannot be used. 
Example 3: Given $U_{6}=10$ hrs and $L C=72 \%$, what is the total time taken to complete units 1 through 6 ?

Typical Student Response: The formula is used.

While the student response is correct, it is a good idea to demonstrate to them that using the formula for the entire problem can be time consuming. We stress upon the fact that there is no known closed form expression or cumulative formula for

$\mathrm{U}_{1}+\ldots+\mathrm{U}_{n}=\mathrm{U}_{1}\left(1^{\mathrm{b}}+\ldots+n^{\mathrm{b}}\right)=\mathrm{U}_{1} \sum^{\mathrm{n}} i^{\mathrm{b}}$ in order to calculate the sum of $n$ units. $i=1$

Here, an alert student usually points out that $U_{3}$ can be obtained straight from the property since $U_{6}$ is given and once $\mathrm{U}_{1}$ is found using the formula, units $\mathrm{U}_{2}$ and $\mathrm{U}_{4}$ can be obtained using the property. Finally, $\mathrm{U}_{5}$ has to be found using the formula. Hence, the quick approach is to use the formula for units 1 and 5 , and the property for units 2,3 , and 4 .

For the case where $\mathrm{LC}=80 \%$ in the above example, the fastest approach would be to simply calculate $\mathrm{U}_{1}$ and then obtain the cumulative value using the Table of values.

We also explain the idea of building a model or a formula with a simple number series based example.

Example 4: Consider the number series 2, 5, 10, 17, 26, 37, 50, ......

Students are often able to identify the next number in this series, but their method (which is usually the series of the differences between the above numbers) is time consuming to identify; for instance, the $20^{\text {th }}$ number in this series. We point out that these numbers are in the form $1^{2}+1,2^{2}+1,3^{2}+1 \ldots$ and that the $20^{\text {th }}$ number will be $20^{2}+1$ and, in general, the $n$th number in this series will be $n^{2}+1$. We illustrate this only to drive home the point that the model $U_{n}=U_{1}^{*} n^{\mathrm{b}}$ is also built by carefully studying such patterns of numbers. The students then understand and appreciate the LC formula.

Finally, we present Table 2 which summarizes the discussion of the above methods.

Table 2: A Comparison of the Three Methods

\begin{tabular}{|l|l|l|}
\hline a. Property & b. Table of values & c. Formula \\
\hline $\begin{array}{l}\text { Advantage. Very quick method in most } \\
\text { cases }\end{array}$ & $\begin{array}{l}\text { Advantage. Can calculate cumulative } \\
\text { values }\end{array}$ & $\begin{array}{l}\text { Advantage. Can calculate any unit value } \\
\text { for any LC }\end{array}$ \\
$\begin{array}{l}\text { Limitation. Can only calculate specific } \\
\text { unit values depending on what units fall } \\
\text { in the doubling of repetitions process }\end{array}$ & $\begin{array}{l}\text { Limitation. Textbooks present specific } \\
\text { LC percentages for up to 30 units. } \\
\text { Otherwise, there is no limitation since a } \\
\text { spreadsheet can create a Table of values } \\
\text { for any LC. }\end{array}$ & $\begin{array}{l}\text { Limitation. There is no closed form } \\
\text { values. }\end{array}$ \\
\hline
\end{tabular}

By this time, the student is well equipped to solve some textbook based problems. Recently, we exposed our students to the NASA website - http://cost.jsc.nasa.gov/learn.html - that has a tool which allows us to perform simple learning curve calculations online. This provides immediate answers to the cumulative average, cumulative total, and the time taken for the $n$th effort for any number of units.

Finally, we demonstrate the implementation of the formula on a spreadsheet. Given the learning rate and the time for the first unit, the spreadsheet can rather easily compute the time for the $\mathrm{n}^{\text {th }}$ unit, the cumulative total and the cumulative average, and plot these in a graph. Given the time for the $\mathrm{k}^{\text {th }}$ unit instead of the time for the first unit, one can perform "goal seek" to find the time for the $\mathrm{n}^{\text {th }}$ unit. The spreadsheet approach is always very useful in order to enhance the students' spreadsheet skills. 


\section{SUMMARY}

We compared and summarized the three methods of Learning Curves calculations in a systematic manner. We have been successful in enhancing the students' understanding of these methods with our comparative charts. We observed that this approach has helped the students in choosing the best method during a time-based exam. We also discussed an error and ambiguity in textbooks. Our teaching approach involves a hands-on exercise to learn the key concepts, several problem-solving exercises using the proposed comparative charts, and finally the use of spreadsheets. This has kept our classes lively and interactive and also increased the understanding of this important topic among our students.

\section{AUTHOR INFORMATION}

Jaideep Naidu is an Associate Professor of Operations Management and Management Science at the School of Business Administration, Philadelphia University. He holds a Ph.D. in Operations Management from The University of Mississippi. His research interests center on machine scheduling problems and higher education. Among other journals, his work has appeared in Journal of the Operational Research Society, Omega - The International Journal of Management Science, and International Journal of Operations and Quantitative Management. E-mail: naiduj@philau.edu (Corresponding author)

John Sanford is a Professor of Information Systems at the School of Business Administration, Philadelphia University. He received Doctor of Engineering degree from Yale University 1963. His interests include information systems, Data Analysis, and data Analysis with Fuzzy Systems. He has published in Proceedings of the Northeast Decision Sciences, Proceedings of IABPAD New Orleans, and The International Journal of Teaching \& Case Studies IJTCS. E-mail: sanfordj@philau.edu

\section{REFERENCES}

1. Bai, J., Wang, M-Z., and Wang, J-B, Single Machine scheduling with a general exponential learning effect, Applied Mathematical Modeling, 36 (2), February 2012, 829 - 835.

2. Heineke, Janelle N. and Meile, Larry C. (1995), Games and Exercises for Operations Management: HandsOn learning Activities for Basic Concepts and Tools, Prentice Hall, New Jersey.

3. Krajewski, L.J., Ritzman L.P. and Malhotra, M. (2010), Operations Management: Processes and Supply Chains, 9/e, Prentice Hall, New Jersey.

4. Martinich J.S. (1997), Production and Operations Management: An Applied Modern Approach, John Wiley \& Sons, New York, NY.

5. Paxton, J., A Short, Simple Learning Curve Classroom Exercise, The Decision Sciences Journal of Innovative Education, 1 (2), Fall 2003, 303 - 307.

6. Rudek, R., Computational complexity and solution algorithms for flowshop scheduling problems with the learning effect, Computers and Industrial Engineering, 61 (1), August 2011, 20 - 31.

7. Stevenson, William J. (2011), Operations Management, 11/e, McGraw-Hill Irwin, New York, NY.

8. Wright, T.P., Factors affecting the cost of airplanes, Journal of Aeronautical Sciences. 3, 1936, 122 - 128.

9. http://cost.jsc.nasa.gov/learn.html 
NOTES 